\section{Unusual Presentation of Carcinoma of the Colon}

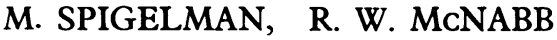

British Medical fournal, 1971, 4, 534

The common association of iron-deficiency anaemia with colonic cancer makes it likely that controlled release iron tablets or other treatment will be undertaken. The case described below illustrates an unusual presentation of carcinoma of the colon due to this and involving a preparation of dried ferrous sulphate given over a fairly long period.

\section{Case Report}

A 71-year-old woman was referred to the outpatient department on 20 August 1970 with a history of iron-deficiency anaemia for three and a half years, weight loss of $9.5 \mathrm{~kg}$ in 18 months and one episode of suspected "haematuria."

She had consulted her general practitioner in February 1967 and was found to have an iron-deficiency anaemia (haemoglobin $8 \mathrm{~g} / 100 \mathrm{ml}$ ). A course of iron preparation was given by intramuscular injection until May 1969, when her haemoglobin was $14 \mathrm{~g} / 100 \mathrm{ml}$. Treatment was then changed to one tablet of dried ferrous sulphate preparation (Ferro-Gradumet) daily. She took these until one year later when she was referred to this hospital.

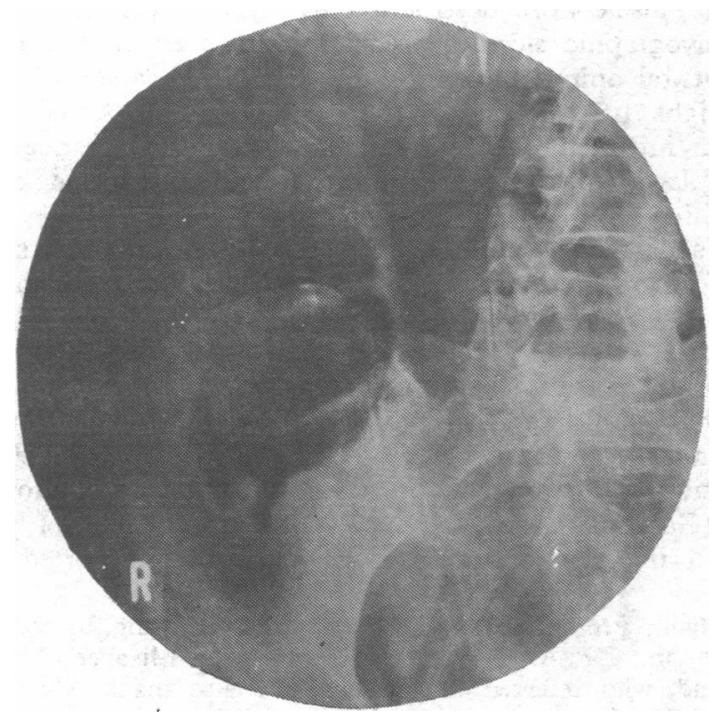

FIG. 1-Large group of oval densities with translucent centres in the right iliac fossa.

After close questioning it was felt that the blood was more likely to have been passed rectally. There was, however, no history of abdominal trouble or change of bowel habit. On examination the only notable finding was of a soft cystic swelling in the right iliac fossa. The $x$-ray appearances are shown in Fig. 1. An intravenous pyelogram with tomography further outlined the features of the swelling and showed normal renal function. A barium-enema examination was next undertaken and showed an obstruction at the hepatic flexure. The suggestion was made that

\section{St. Albans City Hospital, Hertfordshire}

M. SPIGELMAN, F.R.C.S., Surgical Registrar

R. W. MCNABB, D.M.R.D., Consultant Radiologist the opacities were tablets trapped in the right colon by a neoplastic stricture (Fig. 2).

At laparotomy a tumour was found encircling and obstructing the colon $12 \mathrm{~cm}$ above the ileocaecal valve. A right hemicolectomy was performed. The tumour was $8 \mathrm{~cm}$ long and was invading but not perforating the muscle coat. The lymph nodes were not involved. Several of the tablets were enmeshed in the papillae of

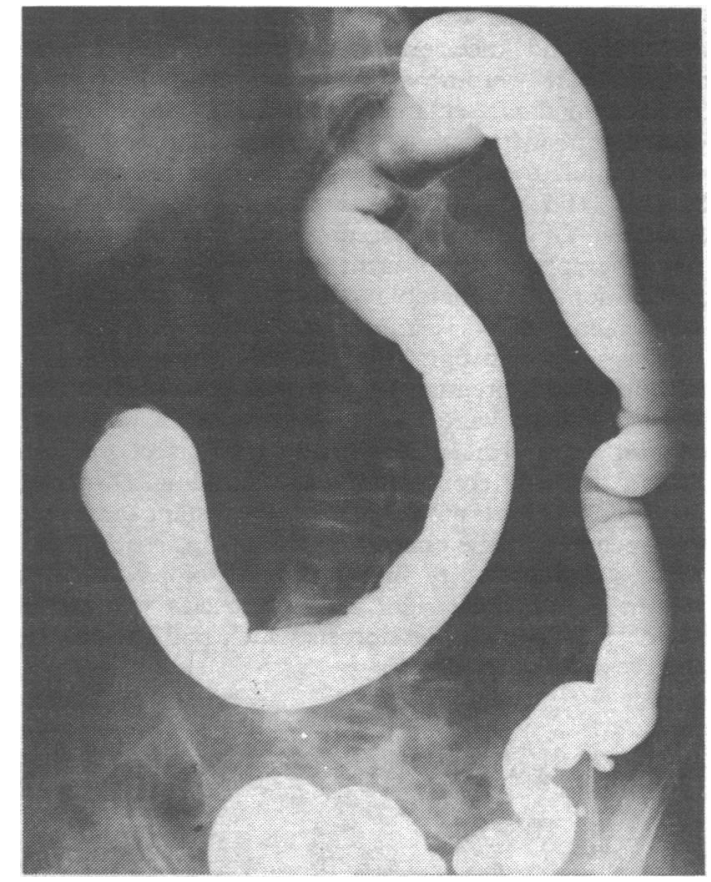

FIG. 2-Colonic obstruction just to the left of the hepatic flexure. Oval densities are present in the right iliac fossa.

the growth (J. I. Pugh). Ninety-eight Ferro-Gradumet tablets were recovered from the colon proximal to the growth. At the time of operation the patient had not been taking the tablets for two months, and they represented one-fifth of her total intake. Analysis of the tablets showed that they contained $9 \mathrm{mg}$ of elemental iron per tablet. (Ferro-Gradumet tablets contain an average of $105 \mathrm{mg}$ of elemental iron).

\section{Comment}

Ferro-Gradumet tablets have an inert plastic matrix base (Gradumet) honeycombed by minute passages. These contain ferrous sulphate which is leached out by the intestinal juices. The base is passed unaltered in the stool. In the presence of a stricture the unaltered base can be trapped indefinitely, as shown in Figs. 1 and 2. It would therefore seem unwise to give this preparation to patients with conditions associated with strictures-for example, Crohn's disease.

The opacity of this preparation is due to the retained iron in the base, because we found that other Gradument preparations (theophylline and Nembutal Gradumet-not at present available in the U.K.) were only faintly opaque to $x$ rays and did not show up on an $x$-ray film of the abdomen when ingested.

Attention was first drawn to this case of carcinoma of the colon by the presence of the remains of Ferro-Gradumet tablets in the right colon. It is not unlikely that such a presentation will become more common if this type of iron preparation comes into more frequent use.

We are grateful to Mr. J. C. F. Townsend for permission to report this case, and to Dr. A. Yeadon, of Abbott Laboratories, for help with iron content estimation and supply of Gradumet base and Nembutal Gradumet. 